\title{
The impact of a better-seeing eye and a worse- seeing eye on vision-related quality of life
}

\author{
This article was published in the following Dove Press journal: \\ Clinical Ophthalmology \\ 3 September 2014 \\ Number of times this article has been viewed
}

\author{
Christoph Hirneiss \\ Department of Ophthalmology, \\ Ludwig Maximilians University \\ Muenchen, Munich, Germany
}

Correspondence: Christoph Hirneiss Ludwig Maximilians University Muenchen, Department of Ophthalmology, Klinikum der Universität München, Campus Innenstadt, Mathildenstrasse 8, D-80336 Munich, Germany $\mathrm{Tel}+498951605160$ Fax +49 9|3I 5I60 305। Email christoph.hirneiss@med.unimuenchen.de
Purpose: Patients with eye diseases often have a better-seeing eye (BSE) and a worse-seeing eye (WSE). This review will carve out the current knowledge in which the relationship to BSEs and WSEs contributes to overall visual functioning and vision-related quality of life (VRQoL).

Methods: Searches were from database inception to the current date. Terms used for the search were "better eye", "worse eye", "utility", "life quality", "quality of life", "VFQ-25", and "visual acuity".

Results: There is a lack of a clear definition for BSE and WSE, and the used definitions are regularly dependent on the underlying eye disease. "BSE" and "WSE" can interact in terms of binocular inhibition or summation. Measured influences of the BSE and WSE on VRQoL are dependent on the underlying instrument used for the measurement. Several studies show impaired VRQoL if only one eye is affected from disease, with unimpaired vision of the BSE. VRQoL can improve significantly when treating the BSE and the WSE. In eye diseases with impairment of the central vision, there is a better correlation between the BSE and VRQoL. However, in eye diseases with peripheral vision impairment, eg, glaucoma, functional parameters of the WSE are better predictors for VRQoL.

Conclusion: The WSE appears to have a stronger influence on VRQoL than is generally assumed. This is especially the case if the underlying eye disease does not affect central vision but peripheral vision.

Keywords: life quality, utility, better eye, worse eye, visual field

\section{Introduction}

Economic evaluation of interventions in eye health is met with the fact that most people have two eyes with often varying levels of functioning, which contributes to overall visual function and vision-related quality of life (VRQoL). Patients with eye diseases regularly have a better-seeing eye (BSE) and a worse-seeing eye (WSE). It is challenging to assess how much each eye separately contributes to that overall visual functioning. In economic evaluations utilities are frequently derived from the BSE or are differentiated between the treatment of the BSE and the WSE. ${ }^{1}$ However, there is an ongoing discussion on the prioritization of different eye care interventions based on their effect on QoL, and for decision making there is no clear consensus if a BSE or a WSE is affected.

Past guidelines have recommended that treatment for disorders affecting both eyes are made available only for the better eye, as demonstrated by the 2007 draft guidance on the use of Lucentis ${ }^{\circledR}$ (Ranibizumab, Novartis Pharma, Basel, Switzerland) in neovascular age-related macular degeneration (AMD) published by the National Institute for Health and Clinical Excellence (NICE) in the UK. ${ }^{2}$ However, very few data are available on the differential impact of combined visual acuity (VA) for BSEs and WSEs. ${ }^{3}$ It can be assumed that impaired vision in the WSE could lead to a loss of VRQoL due to the anxiety of losing vision in the BSE. However, mechanisms 
like adaption could diminish this effect. In addition to that, meanwhile there are many different instruments in ophthalmology to measure VRQoL, and also for specific eye diseases like age-related maculopathy ${ }^{4,5}$ or glaucoma, ${ }^{6}$ and to estimate utilities.

This review summarizes relevant literature for the impact of binocular vision on VRQoL, with special regard to BSEs and WSEs.

\section{Methods}

Searches were from database inception to the current date. Electronic databases searched included MEDLINE (Ovid), MEDLINE In-Process (Ovid), and EMBASE (Ovid). The searches were restricted to the English and German languages. Bibliographies of related papers were screened for relevant studies. The literature had to be published in a peer review journal. Terms used for the search were "better eye", "worse eye", "utility", "life quality", "quality of life", "VFQ-25", and "visual acuity". After the semistructured search of the current literature, the articles were checked for their eligibility to give information about the impact of bilateral vision on VRQoL, and summarized. A very strict process, as is usual, for systematic reviews was regarded to be suboptimal for the purpose of the paper. The results found were ordered systematically to give a thematically reasonable overview, focusing also on physiological aspects in the interaction between the eyes.

\section{Results}

The number of publications specifically looking at the distinct influence of BSEs and WSEs on VRQoL is rather low and heterogeneous. For example, the keywords "worse eye" and "quality of life" results in 47 citations (7 May 2014). To form a feasible structure of our findings, this results section is divided into specific topics.

\section{Definition of the BSE/WSE}

One of the things one should be aware of is the question of how the BSE and the WSE are defined. Although this might sound trivial, this is a major axiom of future calculations, analyses, and conclusions. The definition can focus on either the central vision, which is majorly reflected by the central $\mathrm{VA}$, or peripheral vision loss, which is majorly reflected by defects in the visual field (VF). There has already been an attempt to divide the items of the National Eye Institute 25-item Visual Function Questionnaire (VFQ-25) into central vision loss and peripheral vision loss items to allow for the different vision health states. ${ }^{7}$

\section{Definition of the BSE/WSE by VA}

The most common parameter to decide which eye of the patient is the BSE is the central VA, and the eye with the higher VA is defined as the BSE. This might be an appropriate approach in many patients, but there is more to good vision than 20/20 acuity, and central VA is only one parameter of visual function. It is possible to have good central VA but poor self-reported quality of vision. Low and changing light levels, stereopsis, glare, and low contrast can cause significant impairment despite having good VA. ${ }^{8}$ The reverse is also true.

Bressler et $\mathrm{al}^{9}$ give a VA-based definition of BSE and WSE, taking into account the baseline VA of both eyes (Table 1). However, the defined cutoffs of five and ten letters have to be seen critically, as the standard error of distance VA is about five to eight letters, and in patients with AMD it is even more (up to 15 letters). Furthermore, the measurement of VA is dependent on the method, and measuring VA with Snellen charts is not equal to measuring VA with the Early Treatment of Diabetic Retinopathy Study (ETDRS) charts. It is well known that VA scores are significantly better on ETDRS charts compared with Snellen charts. ${ }^{10,11}$ This also concerns the acceptable differences in repeatability, which have to be taken into account.

\section{Definition of the BSE/WSE by VF}

VF defects and decreased VF sensitivity can cause functional impairments with lower utility ratings. ${ }^{12,13}$ This can be the case in spite of full central VA. If both eyes have good VA, the eye with the better sensitivity on VF testing can be

Table I Definition of the best-seeing eye, the worse-seeing eye, and equal vision described by Bressler et al

\begin{tabular}{|c|c|c|c|}
\hline & Better-seeing eye & Worse-seeing eye & Equal vision \\
\hline $\begin{array}{l}\text { Baseline VA letter score in both } \\
\text { eyes is } \geq 50(20 / 100)\end{array}$ & $\begin{array}{l}\text { Baseline VA of the study eye } \\
\text { is better than that of the fellow } \\
\text { eye by } \geq 5 \text { letters }\end{array}$ & $\begin{array}{l}\text { Baseline VA of the study eye } \\
\text { is worse than that of the fellow } \\
\text { eye by } \geq 5 \text { letters }\end{array}$ & $\begin{array}{l}\text { Baseline VA of the study eye } \\
\text { is within } \pm 4 \text { letters of that } \\
\text { of the fellow eye }\end{array}$ \\
\hline $\begin{array}{l}\text { Baseline VA letter score in one } \\
\text { or both eyes is }<50(20 / 100)\end{array}$ & $\begin{array}{l}\text { Baseline VA of the study eye } \\
\text { is better than that of the fellow } \\
\text { eye by } \geq 10 \text { letters }\end{array}$ & $\begin{array}{l}\text { Baseline VA of the study eye } \\
\text { is worse than that of the fellow } \\
\text { eye by } \geq 10 \text { letters }\end{array}$ & $\begin{array}{l}\text { Baseline VA of the study eye } \\
\text { is within } \pm 9 \text { letters of that } \\
\text { of the fellow eye }\end{array}$ \\
\hline
\end{tabular}

Note: Reprinted from Ophthalmology 20I0; II7, Bressler NM, Chang TS, Suner IJ, et al, Vision-related function after ranibizumab treatment by better- or worse-seeing eye: clinical trial results from MARINA and ANCHOR, 747-756. Copyright @2010 with permission from Elsevier. ${ }^{9}$

Abbreviation: VA, visual acuity. 
considered to be the BSE. However, there is no convention to decide on the BSE/WSE when there is an eye with good central VA and highly impaired VF and a fellow eye with a good (peripheral) VF but low central VA (eg, a patient with asymmetrical glaucomatous defects and macular degeneration). The impairment of the VF is of special importance in patients with glaucoma, who can typically have advanced impairment of the VF despite preserved good central VA. Whether the VA of the BSE or the VA of the WSE has a stronger influence on VRQoL is under discussion. ${ }^{14-16}$ When comparing VA and VF, there is some evidence that the central VA influences the VRQoL to a greater extent than peripheral vision. ${ }^{17}$ There is increasing evidence that poorer VRQoL in glaucoma patients is associated with increasingly WSE VF loss, but not that with a lower association of BSE. ${ }^{18}$ A better nonglaucomatous eye might not fully compensate for the glaucomatous worse eye, indicating the importance of preserving the existing VF in the worse eye. When the VF is used to determine the BSE or the WSE, the VF index mean defect (MD) of the BSE and the WSE has a very similar impact on VRQoL. Some studies report a (slightly) higher influence of the MD-based BSE on VRQoL, ${ }^{19-21}$ but there are other investigations that report a higher influence of the MD-based WSE on VRQoL. ${ }^{22}$ With regard to VA in patients with glaucoma, there is repeated evidence that the eye with the lower VA is more strongly correlated with VRQoL. ${ }^{19,20}$ In a study from Gothwal et $\mathrm{al}^{19}$ the correlation of patient-reported visual functioning using Glaucoma Activity Limitation 10 score with the VA of the WSE was $r=0.49$, whereas it was $r=0.35$ with the BSE. However, concerning VRQoL with regard to the BSE and WSE in patients with peripheral VF defects, it has to be kept in mind that there are different patterns of VF defects, which can make large differences. ${ }^{23,24}$ However, the VA of the WSE and the MD of the BSE can significantly predict VRQoL in glaucoma patients. There is also a correlation between structural parameters of the WSE (but not the BSE) and VRQoL. ${ }^{25}$ There have also been attempts to use binocular VF tests for correlation analyses with VRQoL, which were not superior to the combination of the two monocular VFs. ${ }^{26}$

\section{Choice of the instrument for utility/QoL assessment}

It is of great importance which instrument is used to capture utilities or VRQoL, to detect the influence of the BSE or WSE. For example, in patients with diabetic retinopathy, time trade-off (TTO), EuroQol visual analog scale (EQ-VAS), VFQ-25, and Health Utility Index-3 (HUI-3) could detect significant differences in scores between patient groups classified according to visual impairment in the BSE, but only HUI-3 and EQ-VAS detected significant differences between patient groups classified according to visual impairment or pathological progression in the WSE. ${ }^{27}$

VRQoL measurements are strongly dependent on the nature of the used items. For example, if only items are used that ask for central vision, VF loss is not relevant for whatever is measured with these instruments. The most commonly used instrument in ophthalmology to measure VRQoL is the VFQ-25. ${ }^{28}$ Using modern probabilistic test theory (Rasch analysis) it was shown that the originally defined 12 -factor structure has suboptimal psychometric validity and that flaws should be remediated. ${ }^{7,29,30}$ For a better comparison and unless Rasch calibrated versions are used more widely, the conventional form with composite and subscale scores is applied for analysis.

\section{Overview of studies that investigated BSE/WSE}

In the overview of studies that investigated BSE and WSE, one major differentiation in two kinds of studies can be identified: 1) studies that investigate the influence of the BSE and WSE on VRQoL in a cross-sectional manner with various underlying eye diseases, and 2) studies that look longitudinally at the development of VRQoL when it comes to changes in the BSE or WSE.

\section{Cross-sectional BSE/WSE studies}

One of the first studies that investigated the influence of BSE and WSE on VRQoL was performed in 2001 by Brown et al. ${ }^{31}$ Using TTO to assess utility values, patients with good VA in one eye had a TTO value of 0.89 , whereas the mean TTO value in patients with good vision in both eyes was 0.97 . Table 2 displays utility values for the WSE stratified by good VA of the fellow eye (BSE). However, for most of the groups the respective number of patients was low, and to that time

Table 2 Utility values for the worse-seeing eye stratified by good visual acuity of the fellow eye

\begin{tabular}{ll}
\hline $\begin{array}{l}\text { Vision in the worse-seeing eye } \\
\text { (fellow eye good vision) (ranges given) }\end{array}$ & $\begin{array}{l}\text { Time trade-off utility } \\
( \pm \text { standard deviation) }\end{array}$ \\
\hline 20/40-20/50 $(0.5-0.4 ; n=24)$ & $0.87(0.16)$ \\
20/70-20/I00 $(0.28-0.2 ; n=12)$ & $0.90(0.16)$ \\
20/200-20/400 (0.I-0.05; $n=0.13)$ & $0.94(0.13)$ \\
Counting finger-light perception $(n=25)$ & $0.88(0.18)$ \\
No light perception $(n=6)$ & $0.81(0.16)$ \\
\hline
\end{tabular}

Note: Reprinted from Ophthalmology 200I;108, Brown MM, Brown GC, Sharma S, Busbee B, Brown $\mathrm{H}$. Quality of life associated with unilateral and bilateral good vision, 643-647, discussion 647-648. Copyright $\odot 200$ I with permission from Elsevier. ${ }^{31}$ 
point it was unclear whether worsening vision in the WSE was associated with a decrease in utility or VRQoL.

However, this phenomenon was observed repeatedly. In a recent submission from Finger et $\mathrm{al}^{32}$ of 1,339 participants the VRQoL was assessed by the Vision and Quality of Life Index (VisQol), ${ }^{33,34}$ which is supposed to display utilities and ranges from 0 to 1 . Patients were stratified according to their VA in both the BSE and the WSE. The VA categories were no visual impairment (VA 0.5 or better), mild visual impairment (VA 0.32-0.5), and moderate to severe visual impairment (VA worse than 0.32 ). Table 3 displays the VisQol utility states for each category combination. It can be clearly seen that VRQoL decreases significantly when there is severe visual impairment in one eye but there is no impairment in the fellow eye, with a disutility of up to 29 utilities. In a cross-sectional study by Soubrane et $\mathrm{a}^{35}$ patients with bilateral neovascular AMD and good VA in one eye were compared with controls without AMD who were matched according to their VA. The patients with one good eye still report worse vision-related functioning.

In AMD there is evidence that patients with bilateral manifestation of the disease report lower VRQoL when compared with patients with unilateral manifestation. ${ }^{36}$ The difference, even after adjusting for VA, was six points in the VFQ-25, which is a clinically meaningful difference even from a conservative point of view (minimal clinically important difference [MCID] of four to six points). In a study by Awdeh et $\mathrm{al}^{37}$ in patients with unilateral branch retinal vein occlusion, a decrease in VFQ-25 score was correlated with the VA of the eye involved, even with good VA of the fellow eye.

\section{Longitudinal BSE/WSE studies}

Longitudinal studies allow the follow-up of the BSE/WSE and the changes in VRQoL. If the VRQoL changes over time, it should be decided whether this change is relevant for the patient's perception - in particular, whether it is clinically meaningful for the patient. Using anchor-based methods assuming a two-line change in VA of the BSE to be clinically relevant, the Submacular Surgery Trials (SST)
Research Group calculated a three-point to four-point change (mean 3.6 points) in the VFQ-25 composite score to be the MCID. ${ }^{38}$ Other studies report that a five-point shift or difference is considered meaningful to subjects. ${ }^{39,40}$ In a recent distribution-based approach using half of the standard deviation, the MCID of the VFQ composite score was determined to be at a six-point shift, ${ }^{41}$ and Suner et $\mathrm{al}^{42}$ estimated a change of four to six points to represent a clinically meaningful change corresponding to a 15-letter (three lines) change in VA. However, the German independent scientific institution, the Institution for Quality and Efficiency in Health Care has accepted a 3.6-point change to be clinically relevant (https:// www.iqwig.de/en/projects results/projects/drug assessment/ a13 20 ocriplasmin benefit assessment according to $35 \mathrm{a}$ social code book v dossier assessment.3662.html).

Multiple studies evaluating self-reported visual function outcomes of cataract extraction in the second eye of patients with bilateral cataract demonstrate that second eye surgery (ie, surgery on the WSE, assuming that the first eye surgery was a success and that there are no ocular morbidities in the first eye) confers significant self-reported visual function benefits. ${ }^{43-46}$ Second eye cataract surgery not only improves VRQoL significantly but also it was shown to be very costeffective. ${ }^{47}$ In patients with macular holes undergoing vitrectomy, a significant increase in VRQoL was noted, although in all included patients it was the WSE that underwent surgery, and the BSE had a VA of mean $0.8 .^{48}$ The mean gain in the VFQ composite score was 5.6 points and therefore clinically meaningful for the patients. For patients with neovascular AMD, Bressler et $\mathrm{al}^{9}$ analyzed the data from two large studies, MARINA (Minimal Classic/Occult Trial of the Anti-VEGF Antibody Ranibizumab in the Treatment of Neovascular AMD) and ANCHOR (Anti-VEGF Antibody for the Treatment of Predominantly Classic Choroidal Neovascularization in AMD), with regard to the change of VRQoL and the treatment of either the BSE or the WSE with ranibizumab intravitreally. It could be shown that the VRQoL, measured with the VFQ-25, improved regardless of whether the treated eye was the BSE or the WSE. It has to be noted that in the study sample about two-thirds of the treated eyes were the

Table 3 Vision and Quality of Life Index utility states stratified according to patients' visual acuity in both the better-seeing eye (BSE) and the worse-seeing eye (WSE) (mean utility values \pm standard deviation are displayed)

\begin{tabular}{lllll}
\hline & & & \\
\cline { 3 - 4 } & & NSE & Mild & Moderate/severe \\
\hline BSE & No impairment & $0.95 \pm 0.10$ & $0.90 \pm 0.16$ & $0.86 \pm 0.17$ \\
& Mild & & $0.85 \pm 0.17$ & $0.84 \pm 0.19$ \\
& Moderate/severe & & & $0.71 \pm 0.28$ \\
\hline
\end{tabular}

Note: Reproduced from Finger RP, Fenwick E, Hirneiss CW, et al. Visual impairment as a function of visual acuity in both eyes and its impact on patient reported preferences. PLoS One. 2013;8:e81042.32 
WSEs. However, treating the WSE improved VFQ-25 scores up to 2.6 points after 24 months, which is below the MCID for the VFQ-25. Another study followed up treatment-naïve patients with neovascular AMD under real-life conditions. ${ }^{3}$ An overall increase in the VFQ-25 composite score of 3.6 points after 1 year was observed with no significant difference in the increase of VRQoL if the BSE or the WSE was treated. In a recent publication by Finger et $\mathrm{al}^{5}$ it could be confirmed that treatment for neovascular AMD improves patients' VRQoL in those who gain vision, and maintains VRQoL in those who maintain VA in their treated eye, irrespective of whether the WSE or the BSE is treated.

\section{Underlying eye disease}

The decline of VRQoL with worsening vision impairment has been shown for Western countries ${ }^{49-52}$ and Asia. This decline was generally described to be independent of specific ocular conditions such as glaucoma or diabetic retinopathy, suggesting that VRQoL is affected across ocular conditions once eyes reach the severe stage of disease, where distance VA and VF may be considerably affected. However, with regard to less severe stages of the distinct eye diseases, this generalization is not likely to be acceptable.

\section{Binocular vision}

When parameters of vision like VA or contrast sensitivity are recorded, this has to be done for each eye separately but also in a binocular manner to contribute for binocular summation. The information about the BSE and the WSE is integrated to form the perception of binocular vision within the postgeniculate pathway. ${ }^{53}$ Binocular summation is defined as the difference between the binocular and BSE VA. ${ }^{54}$ Vision is improved under binocular viewing conditions when compared with scores for each eye individually. However, in patients with large interocular differences in contrast sensitivity, the phenomenon of "binocular inhibition" can also be observed..$^{55}$ Sometimes it is more comfortable for patients to cover the WSE and look only with the BSE. In the case of binocular inhibition due to one eye falling under a critical threshold, ${ }^{56-58}$ it is possible to reduce this inhibition or increase binocular summation when treatment of the WSE can improve vision in this eye.

\section{Discussion}

The current literature that analyzes both eyes of patients with a BSE and a WSE highlights that improving the visual function, eg, VA, or preventing VF loss in the WSE is beneficial for patients' vision-related function and VRQoL. All considerations concerning the BSE and WSE have to include at least two things: the baseline VA or VF impairment for each eye and the threshold for a clinically meaningful improvement or worsening. Such a threshold may be reached if good reading under binocular conditions is no longer possible (or is possible again). This threshold of reading is often described as a VA of 20/40 (binocular or in the BSE). The following case might illustrate in this context the importance of the WSE. A patient with cataract and macular degeneration has a VA of 20/25 in the BSE and 20/50 in the WSE. Reading under binocular conditions would be no problem, and cataract surgery on the BSE or WSE is likely to only slightly increase his or her VRQoL. With progression of the macular degeneration on the BSE the VA might drop to 20/50, with stable VA in the fellow eye, so both eyes now have an equal VA but reading will be much more difficult for the patient, with a dramatic loss in VRQoL. Now, the effect of an intervention for the former WSE, eg, cataract surgery, bringing the eye over the reading threshold, will result in a much higher increase of VRQoL. In case of binocular summation, improving the WSE may lead to a better binocular VA and/or VRQoL, and this might also be the case in binocular inhibition when improving the WSE leads to the disappearance of that phenomenon. With regard to eye diseases that affect the peripheral vision, eg, glaucoma, the VA of the WSE has a stronger influence than the VA of the BSE. These recent findings regarding the influence of peripheral VF defects on VRQoL do not support the hypothesis that VRQoL is independent of the underlying eye condition.

Treatment strategies that focus on the BSE only are likely to underestimate the impact of visual impairment on VRQoL. In patients with AMD, VRQoL or utilities are improved or maintained irrespective of whether the BSE or WSE is treated. ${ }^{3,5}$ Patients with bilateral eye diseases may be constrained by inconvenience, costs, or risks of additional medications or surgery. In the therapeutic decision-making process, the treatment of the WSE should be prioritized more urgently. ${ }^{18}$

Best corrected visual acuity (BCVA) is not the only aspect of vision, and, in that context, WSEs may contribute equally to VRQoL or utility. That is, if utilities are linked to contrast sensitivity, VF, or metamorphopsia (instead of BCVA), an equal gain could be achieved from treating the BSE or the WSE. However, VA should not be directly transferred into VRQoL data or utilities, eg for economic evaluations.' Looking at Tables 2 and 3, this might appear a simple and attractive option, but the proper way to assess utilities is to perform a direct evaluation in every study sample or to use eye disease-specific tables, which are rarely available. Table 3 might serve as a rough utility calculator for patients' AMD, 
but certainly with reduced validity compared with direct evaluation. With regard to the current knowledge concerning the influence of the BSE and the WSE on VRQoL, the NICE argument that only improvements in the BSE drive cost and utility in cost-effectiveness analyses ${ }^{2}$ is not evidence based. The determination of vision-related impairment, eg, for deriving utility values, should be guided by both eyes, with specific attention given to the WSE in cases with a good-seeing (fellow) BSE. The importance of the WSE has considerable implications for defining visual impairment, burden of disease, and economic evaluations. The argument "still got one good eye" is unlikely to reflect the reality of patients' preferences. However, in recent NICE guidance (ranibizumab and fluocinolone acetonide in treatment of macular edema), by exploring different scenarios of the influence of the WSE, the evidence review groups decided to accept a VRQoL function in which treating only the WSE results in $30 \%$ of the range of improvements in vision that would have been achieved by treating only the BSE (http://guidance.nice.org.uk/ta274 and http:// guidance.nice.org.uk/ta301). Nevertheless, this approach is not evidence based and is arbitrary.

Both treatment of the BSE and WSE leads to a benefit in patients' quality of life, contrary to the common assumption that the BSE solely or mostly determines VRQoL. Resource allocation and treatment decisions must not be based on the BSE only, nor must treatments be made available for the BSE in bilaterally affected cases. Evidence strongly suggests that patients should have access to treatment and care when the function in either eye is affected, especially if the underlying eye disease does not affect the central vision but the peripheral vision.

\section{Acknowledgment}

This work has been supported by ThromboGenics.

\section{Disclosure}

The author reports no conflicts of interest in this work.

\section{References}

1. Hurley SF, Matthews JP, Guymer RH. Cost-effectiveness of ranibizumab for neovascular age-related macular degeneration. Cost Eff Resour Alloc. 2008;6:12.

2. NICE issue draft guidance on drugs for the treatment of age related macular degeneration. London, UK: National Institute for Health and Clinical Excellence (NICE); 2007.

3. Finger R, Hoffmann AE, Fenwick EK, et al. Patients' preferences in treatment for neovascular age-related macular degeneration in clinical routine. Br J Ophthalmol. 2012;96:997-1002.

4. Mitchell J, Wolffsohn J, Woodcock A, et al. The MacDQoL individualized measure of the impact of macular degeneration on quality of life: reliability and responsiveness. Am J Ophthalmol. 2008;146: $447-454$.
5. Finger RP, Guymer RH, Gillies MC, Keeffe JE. The impact of antivascular endothelial growth factor treatment on quality of life in neovascular age-related macular degeneration. Ophthalmology. 2014;121(6): 1246-1251.

6. Hirneiss C, Vogel M, Kampik A, Neubauer AS, Kernt M. [Measurement of glaucoma-specific functionality with the GQL-15 and correlation with parameters of visual function]. Ophthalmologe. 2011;108:939-946. German.

7. Kowalski JW, Rentz AM, Walt JG, et al. Rasch analysis in the development of a simplified version of the National Eye Institute Visual-Function Questionnaire-25 for utility estimation. Qual Life Res. 2012;21:323-334.

8. Owsley C, McGwin G, Jackson GR, et al. Effect of short-term, high-dose retinol on dark adaptation in aging and early age-related maculopathy. Invest Ophthalmol Vis Sci. 2006;47:1310-1318.

9. Bressler NM, Chang TS, Suner IJ, et al. Vision-related function after ranibizumab treatment by better- or worse-seeing eye: clinical trial results from MARINA and ANCHOR. Ophthalmology. 2010;117:747-756.

10. Kaiser PK. Prospective evaluation of visual acuity assessment: a comparison of snellen versus ETDRS charts in clinical practice (an AOS thesis). Trans Am Ophthalmol Soc. 2009;107:311-324.

11. Falkenstein IA, Cochran DE, Azen SP, et al. Comparison of visual acuity in macular degeneration patients measured with snellen and early treatment diabetic retinopathy study charts. Ophthalmology. 2008;115:319-323.

12. Kobelt G, Jonsson B, Bergstrom A, Chen E, Linden C, Alm A. Costeffectiveness analysis in glaucoma:what drives utility? Results from a pilot study in Sweden. Acta Ophthalmol Scand. 2006;84:363-371.

13. Nelson P, Aspinall P, O'Brien C. Patients' perception of visual impairment in glaucoma: a pilot study. Br J Ophthalmol. 1999;83:546-552.

14. Janz NK, Wren PA, Lichter PR, Musch DC, Gillespie BW, Guire KE. Quality of life in newly diagnosed glaucoma patients: the Collaborative Initial Glaucoma Treatment Study. Ophthalmology. 2001;108:887-897; discussion 898.

15. Sumi I, Shirato S, Matsumoto S, Araie M. The relationship between visual disability and visual field in patients with glaucoma. Ophthalmology. 2003;110:332-339.

16. Magacho L, Lima FE, Nery AC, Sagawa A, Magacho B, Avila MP. Quality of life in glaucoma patients: regression analysis and correlation with possible modifiers. Ophthalmic Epidemiol. 2004;11:263-270.

17. Yanagisawa M, Kato S, Kobayashi M, Watanabe M, Ochiai M. Relationship between vision-related quality of life and different types of existing visual fields in Japanese patients. Int Ophthalmol. 2012;32:523-529.

18. Chan EW, Chiang PP, Wong TY, et al. Impact of glaucoma severity and laterality on vision-specific functioning: the Singapore Malay Eye Study. Invest Ophthalmol Vis Sci. 2013;54:1169-1175.

19. Gothwal VK, Reddy SP, Bharani S, et al. Impact of glaucoma on visual functioning in Indians. Invest Ophthalmol Vis Sci. 2012;53: 6081-6092.

20. Kulkarni KM, Mayer JR, Lorenzana LL, Myers JS, Spaeth GL. Visual field staging systems in glaucoma and the activities of daily living. Am J Ophthalmol. 2012;154:445-451.

21. van Gestel A, Webers CA, Beckers HJ, van Dongen MC, Severens JL, Hendrikse F, Schouten JS. The relationship between visual field loss in glaucoma and health-related quality-of-life. Eye (Lond). 2010;24: $1759-1769$.

22. Khadka J, Pesudovs K, McAlinden C, Vogel M, Kernt M, Hirneiss C. Re-engineering the Glaucoma Quality of Life-15 Questionnaire with Rasch analysis. Invest Ophthalmol Vis Sci. 2011;52:6971-6977.

23. Park SC, De Moraes CG, Teng CC, Tello C, Liebmann JM, Ritch R. Initial parafoveal versus peripheral scotomas in glaucoma:risk factors and visual field characteristics. Ophthalmology. 2011;118:1782-1789.

24. Murata $\mathrm{H}$, Hirasawa $\mathrm{H}$, Aoyama $\mathrm{Y}$, et al. Identifying areas of the visual field important for quality of life in patients with glaucoma. PLoS One. 2013;8:e58695.

25. Hirneiss C, Reznicek L, Vogel M, Pesudovs K. The impact of structural and functional parameters in glaucoma patients on patient-reported visual functioning. PLoS One. 2013;8:e80757. 
26. Jampel HD, Friedman DS, Quigley H, Miller R. Correlation of the binocular visual field with patient assessment of vision. Invest Ophthalmol Vis Sci. 2002;43:1059-1067.

27. Heintz E, Wirehn AB, Peebo BB, Rosenqvist U, Levin LA. QALY weights for diabetic retinopathy: a comparison of health state valuations with HUI-3, EQ-5D, EQ-VAS, and TTO. Value Health. 2012;15: 475-484.

28. Mangione CM, Lee PP, Gutierrez PR, Spritzer K, Berry S, Hays RD. Development of the 25-item National Eye Institute Visual Function Questionnaire. Arch Ophthalmol. 2001;119:1050-1058.

29. Pesudovs K, Gothwal VK, Wright T, Lamoureux EL. Remediating serious flaws in the National Eye Institute Visual Function Questionnaire. $J$ Cataract Refract Surg. 2010;36:718-732.

30. Marella M,Pesudovs K, Keeffe JE, O'Connor PM, Rees G, Lamoureux EL. The psychometric validity of the NEI VFQ-25 for use in a low-vision population. Invest Ophthalmol Vis Sci. 2010;51:2878-2884.

31. Brown MM, Brown GC, Sharma S, Busbee B, Brown H. Quality of life associated with unilateral and bilateral good vision. Ophthalmology. 2001;108:643-647; discussion 647-648

32. Finger RP, Fenwick E, Hirneiss CW, et al. Visual impairment as a function of visual acuity in both eyes and its impact on patient reported preferences. PLoS One. 2013;8:e81042.

33. Peacock S, Misajon R, Iezzi A, Richardson J, Hawthorne G, Keeffe J. Vision and quality of life: development of methods for the VisQoL visionrelated utility instrument. Ophthalmic Epidemiol. 2008;15: 218-223.

34. Finger RP, Kortuem K, Fenwick E, von Livonius B, Keeffe JE, Hirneiss CW. Evaluation of a vision-related utility instrument: the German Vision and Quality of Life Index. Invest Ophthalmol Vis Sci. 2013;54: 1289-1294.

35. Soubrane G, Cruess A, Lotery A, et al. Burden and health care resource utilization in neovascular age-related macular degeneration: findings of a multicountry study. Arch Ophthalmol. 2007;125:1249-1254.

36. Dong LM, Childs AL, Mangione CM, et al. Health- and vision-related quality of life among patients with choroidal neovascularization secondary to age-related macular degeneration at enrollment in randomized trials of submacular surgery: SST report No. 4. Am J Ophthalmol. 2004;138:91-108.

37. Awdeh RM, Elsing SH, Deramo VA, Stinnett S, Lee PP, Fekrat S. Vision-related quality of life in persons with unilateral branch retinal vein occlusion using the 25-item National Eye Institute Visual Function Questionnaire. Br J Ophthalmol. 2010;94:319-323.

38. Submacular Surgery Trials Research Group. Evaluation of minimum clinically meaningful changes in scores on the National Eye Institute Visual Function Questionnaire (NEI-VFQ) SST Report Number 19. Ophthalmic Epidemiol. 2007;14:205-215.

39. McKean-Cowdin R, Varma R, Hays RD, Wu J, Choudhury F, Azen SP. Longitudinal changes in visual acuity and health-related quality of life: the Los Angeles Latino Eye Study. Ophthalmology. 2010;117: 1900-1907.

40. Matza LS, Rousculp MD, Malley K, Boye KS, Oglesby A. The longitudinal link between visual acuity and health-related quality of life in patients with diabetic retinopathy. Health Qual Life Outcomes. 2008;6:95.

41. Lloyd AJ, Loftus J, Turner M, Lai G, Pleil A. Psychometric validation of the Visual Function Questionnaire-25 in patients with diabetic macular edema. Health Qual Life Outcomes. 2013;11:10.
42. Suner IJ, Kokame GT, Yu E, Ward J, Dolan C, Bressler NM. Responsiveness of NEI VFQ-25 to changes in visual acuity in neovascular AMD: validation studies from two phase 3 clinical trials. Invest Ophthalmol Vis Sci. 2009;50:3629-3635.

43. Castells X, Comas M, Alonso J, et al. In a randomized controlled trial, cataract surgery in both eyes increased benefits compared to surgery in one eye only. J Clin Epidemiol. 2006;59:201-207.

44. Desai P, Reidy A, Minassian DC, Vafidis G, Bolger J. Gains from cataract surgery: visual function and quality of life. Br J Ophthalmol. 1996;80: 868-873.

45. Lundstrom M, Stenevi U, Thorburn W. Quality of life after first- and second-eye cataract surgery: five-year data collected by the Swedish National Cataract Register. J Cataract Refract Surg. 2001;27: 1553-1559.

46. Elliott DB, Patla AE, Furniss M, Adkin A. Improvements in clinical and functional vision and quality of life after second eye cataract surgery. Optom Vis Sci. 2000;77:13-24.

47. Busbee BG, Brown MM, Brown GC, Sharma S. Cost-utility analysis of cataract surgery in the second eye. Ophthalmology. 2003;110: 2310-2317.

48. Hirneiss C, Neubauer AS, Gass CA, et al. Visual quality of life after macular hole surgery: outcome and predictive factors. Br JOphthalmol. 2007;91:481-484.

49. Broman AT, Munoz B, Rodriguez J, et al. The impact of visual impairment and eye disease on vision-related quality of life in a MexicanAmerican population: proyecto VER. Invest Ophthalmol Vis Sci. 2002; 43:3393-3398

50. West SK, Munoz B, Rubin GS, et al. Function and visual impairment in a population-based study of older adults. The SEE project. Salisbury Eye Evaluation. Invest Ophthalmol Vis Sci. 1997;38:72-82.

51. Nirmalan PK, Tielsch JM, Katz J, et al. Relationship between vision impairment and eye disease to vision-specific quality of life and function in rural India: the Aravind Comprehensive Eye Survey. Invest Ophthalmol Vis Sci. 2005;46:2308-2312.

52. Vu HT, Keeffe JE, McCarty CA, Taylor HR. Impact of unilateral and bilateral vision loss on quality of life. Br J Ophthalmol. 2005;89: 360-363.

53. Gagnon RW, Kline DW. Senescent effects on binocular summation for contrast sensitivity and spatial interval acuity. Curr Eye Res. 2003;27: 315-321.

54. Blake R, Sloane M, Fox R. Further developments in binocular summation. Percept Psychophys. 1981;30:266-276.

55. Pardhan S, Gilchrist J, Elliott DB, Beh GK. A comparison of sampling efficiency and internal noise level in young and old subjects. Vision Res. 1996;36:1641-1648.

56. Pardhan S, Gilchrist J. Binocular contrast sensitivity with monocular glare disability. Ophthalmic Physiol Opt. 1990;10:37-39.

57. Pardhan S, Gilchrist J. The effect of monocular defocus on binocular contrast sensitivity. Ophthalmic Physiol Opt. 1990;10:33-36.

58. Pardhan S, Gilchrist J, Douthwaite W, Yap M. Binocular inhibition: psychophysical and electrophysiological evidence. Optom Vis Sci. 1990; 67:688-691.
Clinical Ophthalmology

\section{Publish your work in this journal}

Clinical Ophthalmology is an international, peer-reviewed journal covering all subspecialties within ophthalmology. Key topics include: Optometry; Visual science; Pharmacology and drug therapy in eye diseases; Basic Sciences; Primary and Secondary eye care; Patient Safety and Quality of Care Improvements. This journal is indexed on Submit your manuscript here: http://www.dovepress.com/clinical-ophthalmology-journal

\section{Dovepress}

PubMed Central and CAS, and is the official journal of The Society of Clinical Ophthalmology (SCO). The manuscript management system is completely online and includes a very quick and fair peer-review system, which is all easy to use. Visit http://www.dovepress.com/ testimonials.php to read real quotes from published authors. 